Original Research Paper

\title{
Insulating Properties of Low Density Polyethylene/Alumina Nanocomposites
}

\author{
${ }^{1}$ Si-Jiao Wang, ${ }^{1,2}$ Jun-Wei Zha, ${ }^{1}$ Yun-Hui Wu, ${ }^{1}$ Hong-DA Yan and ${ }^{1}$ Zhi-Min Dang \\ ${ }^{1}$ Department of Polymer Science and Engineering, University of Science and Technology Beijing, Beijing 100083, P. R. China \\ ${ }^{2}$ State Key Laboratory of Power Transmission Equipment and System Security and New Technology, Chongqing University, \\ Chongqing, 400030, P. R. China
}

Article history

Received: 11-05-2015

Revised: $15-05-2015$

Accepted: 29-05-2015

Corresponding Author:

Jun-Wei Zha

Department of Polymer Science

and Engineering

University of Science and

Technology Beijing

Beijing 100083, P. R. China

Email: zhajw@ustb.edu.cn

\begin{abstract}
High-Voltage Direct Current (HVDC) cable has become an important factor in the development of HVDC transmission. However, there are still difficulties such as space charge distribution in the development of HVDC cables. In this study, Low Density Polyethylene (LDPE) nanocomposites filled with nano alumina (nano- $\mathrm{Al}_{2} \mathrm{O}_{3}$ ) particles with or without modification were prepared by employing melting blend method. The results show that the modified nano- $\mathrm{Al}_{2} \mathrm{O}_{3}$ particles with vinyl silane coupling can be homogeneously dispersed in LDPE matrix. Space charge of the LDPE nanocomposites was tested by Pulsed Electro-Acoustic (PEA) method. The PEA spectrum indicated that decay charge effect of the $\mathrm{LDPE} / \mathrm{Al}_{2} \mathrm{O}_{3}$ nanocomposites is better than that of neat LDPE. The space charge accumulated in the nanocomposites can be effectively decayed. The $J-V$ curves show the nano- $\mathrm{Al}_{2} \mathrm{O}_{3}$ decrease the carrier mobility. The excellent insulation properties of the LDPE nanocomposites were attributed to the better interfacial adhesion between the surface-treated nano- $\mathrm{Al}_{2} \mathrm{O}_{3}$ particles and the matrix.
\end{abstract}

Keywords: Polyethylene, $\mathrm{Al}_{2} \mathrm{O}_{3}$, Composites, Space Charge, Decay, J-V Curves

\section{Introduction}

Low Density Polyethylene (LDPE) is widely used as bulk insulation in extruded cables, but under HighVoltage Direct Current (HVDC) the space charge accumulated in the LDPE can greatly distort the electrical field and then influence the aging property. The reason is probably that the physical and chemical defects existed in LDPE could lead to the increasing local electric field so that the insulating properties would decrease. To solve the problem, the inorganic nanoparticles and polarity substance have been added into PE. The effect of nano-sized particle additives on the electrical properties of dielectrics is currently of considerable interest (Olthuis and Bergveld, 1992; Liu and Chen, 2013; Wu et al., 2014; Kim et al., 2013; Fleming et al., 2011; Ju et al., 2014; Takada et al., 2008; Hosier et al., 2010).

In this study, LDPE nanocmposites filled with the nano- $\mathrm{Al}_{2} \mathrm{O}_{3}$ particles with and without surface modification were prepared. Space charge characteristics in LDPE nanocomposites were measured using the Pulsed Electro Acoustic technique (PEA). The charge decay in both types of the samples was also tested. Traps and carrier mobility of LDPE nanocomposites were also discussed.

\section{Experimental}

\section{Materials}

LDPE (LD200BW) with density of $0.922 \mathrm{~g} / \mathrm{cm}^{3}$ and melt flow rate of $2.3 \mathrm{~g} / 10 \mathrm{~min}$ was purchased from Sinopec Beijing Yanshan Co., China. The nano$\mathrm{Al}_{2} \mathrm{O}_{3}$ particles were supplied by Institute of Process Engineering Chinese Academy of Sciences (China) and they were modified by vinyltrimethoxysilane (VMES, $\mathrm{V}-\mathrm{Al}_{2} \mathrm{O}_{3}$ ) prior to use. The reaction route is presented in Fig. 1. 


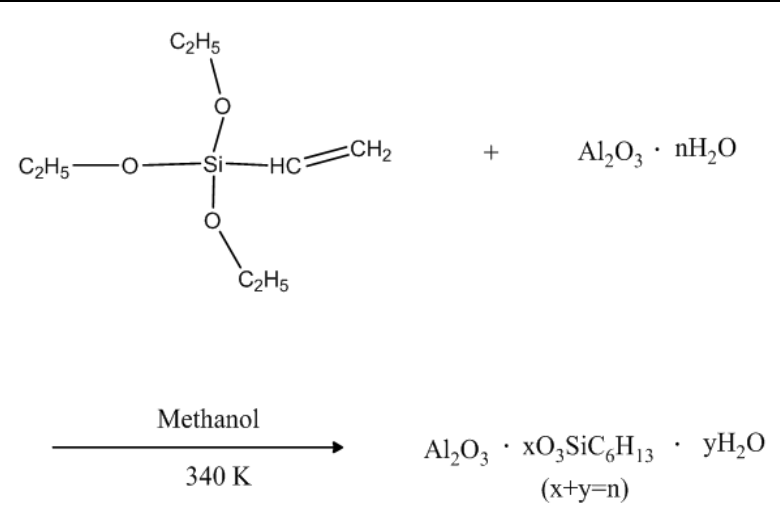

Fig. 1. Schematic of the reactions between the original $\mathrm{Al}_{2} \mathrm{O}_{3}$ and the silane.

The different contents $(0.1,0.2,0.5,1 \mathrm{wt} \%)$ of nano$\mathrm{Al}_{2} \mathrm{O}_{3}$ particles were mechanically mixed with LDPE granules using the HAAKE PolyLab mixer (HAAKE Rheomix 600, Germany) with the processing temperature of $130^{\circ} \mathrm{C}$. The neat LDPE and $\mathrm{Al}_{2} \mathrm{O}_{3} / \mathrm{LDPE}$ nanocomposite films were prepared by a hot-press method at the temperature of $150^{\circ} \mathrm{C}$ and the pressure of $15 \mathrm{MPa}$. The prepared films were placed in a vacuum oven at $80^{\circ} \mathrm{C}$ for $24 \mathrm{~h}$ and then cooled down to room temperature to eliminate thermal history. To banish the remainder charge, the films were put between two polished copper plates in a vacuum oven at $80^{\circ} \mathrm{C}$ for $48 \mathrm{~h}$ short-circuiting.

\section{Characterization}

Carrier mobility of the samples was tested with a Keithley electrometer model 6517 B. The samples with the diameter of $54 \mathrm{~mm}$ and the thickness of $0.4 \mathrm{~mm}$ were prepared for testing. The polarization current was obtained after short-circuiting for $5 \mathrm{~min}$. The polarization voltage was set at $1 \mathrm{kV}$.

The space charge distribution was tested by PEA (Shanghai Jiao Tong University) carried out under an electrical field of $30 \mathrm{kV} / \mathrm{mm}$ for $60 \mathrm{~min}$ at $25^{\circ} \mathrm{C}$. During the measurement, the samples with the size of $400 \mu \mathrm{m}$ $\times 7 \mathrm{~cm} \times 7 \mathrm{~cm}$ were sandwiched between an aluminum electrode and a semi-conductive polymer electrode (the diameter is $12 \mathrm{~cm}$ and $2 \mathrm{~cm}$, respectively).

\section{Results and Discussion}

Figure 2 shows polarization currents measured for 5 min. The current decrease exponentially with time increasing and subsequently reaches an equilibrium value. The polarization currents curves of LDPE reach the equilibrium value at $100 \mathrm{~s}$, while the $\mathrm{Al}_{2} \mathrm{O}_{3} / \mathrm{LDPE}$ nanocomposites filled with $1 \mathrm{wt} \%$ nano- $\mathrm{Al}_{2} \mathrm{O}_{3}$ only at 50 $\mathrm{s}$. The equilibrium value of polarization current of LDPE is much larger than that of $1 \quad w t \% \quad \mathrm{Al}_{2} \mathrm{O}_{3} / \mathrm{LDPE}$ nanocomposite. It could be indicated that a large amount of charges inject into the LDPE. However, the nano$\mathrm{Al}_{2} \mathrm{O}_{3}$ can inhibit the charges to inject into the interior of nanocomposite and prevent most of charges gather on the surface of the samples (Nelson and $\mathrm{Hu}, 2005$ ).

The current density-voltage $(J-V)$ curves obtained from the equilibrium value of polarization current at different voltages were shown in Fig. 3. The $J-V$ curves are consistent with the well-known Mott and Gurney equation (Meunier et al., 2001). At low applied voltages the $J-V$ characteristics may follow Ohm's law:

$$
J=q p_{0} \mu_{\mathrm{p}} \frac{V}{d}
$$

Where:

$p_{0}=$ The density of thermally generated free carriers inside the sample

$\mu_{\mathrm{p}}=$ The carrier mobility

$d=$ The thickness of the sample. The slope of the Equation 1 was given as follow Equation 2:

$k_{1}=q p_{\mathrm{o}} \mu_{\mathrm{p}}$

Due to the increased space charge, quadratic relationship of $J-V$ curves fitting is obtained at high applied voltages as shown by Equation 3:

$$
J=\frac{9}{8} \varepsilon_{\mathrm{r}} \varepsilon_{0} \mu_{\mathrm{p}} \frac{V^{2}}{d^{3}}
$$

where, $\varepsilon_{r}$ is the relative permittivity of the material and $\varepsilon_{0}$ $=8.854 \times 10^{-12} \mathrm{~F} / \mathrm{m}$, is the permittivity of vacuum. Then the carrier mobility $\mu_{\mathrm{p}}$ are calculated from the fitting constants $k$, which have given as follows Equation 4:

$$
k=\frac{9}{8 d^{3}} \varepsilon_{\mathrm{r}} \varepsilon_{0} \mu_{\mathrm{p}}
$$

The carrier mobility of $\mathrm{Al}_{2} \mathrm{O}_{3} / \mathrm{LDPE}$ nanocomposites calculated by the above equations is $1.54 \times 10^{-11} \mathrm{~cm}^{2} /$ $(\mathrm{V} \cdot \mathrm{s})$ and which of the $\mathrm{V}-\mathrm{Al}_{2} \mathrm{O}_{3} / \mathrm{LDPE}$ nanocomposites is $9.97 \times 10^{-12} \mathrm{~cm}^{2} /(\mathrm{V} \cdot \mathrm{s})$, which is lower than the published values of LDPE (Meunier et al., 2001). The addition of $\mathrm{Al}_{2} \mathrm{O}_{3}$ decreases the carrier mobility of composites, especially the $\mathrm{Al}_{2} \mathrm{O}_{3}$ modified by silane coupling agent, about an order of magnitude.

Figure 3 shows the $\mathrm{Al}_{2} \mathrm{O}_{3} / \mathrm{LDPE}$ nanocomposites follow Ohm's law at low applied voltages $(0-200 \mathrm{~V})$ in the $J-V$ curves. It can be seen that the area of the Ohm's law of the $\mathrm{V}-\mathrm{Al}_{2} \mathrm{O}_{3} / \mathrm{LDPE}$ nanocomposites is larger than that of $\mathrm{Al}_{2} \mathrm{O}_{3} / \mathrm{LDPE}$ nanocomposites without modification, indicating that the $\mathrm{V}$ - 
$\mathrm{Al}_{2} \mathrm{O}_{3} / \mathrm{LDPE}$ nanocomposites have better insulation. The $J-V$ curves of $\mathrm{Al}_{2} \mathrm{O}_{3} / \mathrm{LDPE}$ nanocomposites and $\mathrm{V}-\mathrm{Al}_{2} \mathrm{O}_{3} / \mathrm{LDPE}$ nanocomposites are similar to schottky curves. It demonstrates that the main mechanism of charge injected into from electrode to dielectric interface is Schottky injection.

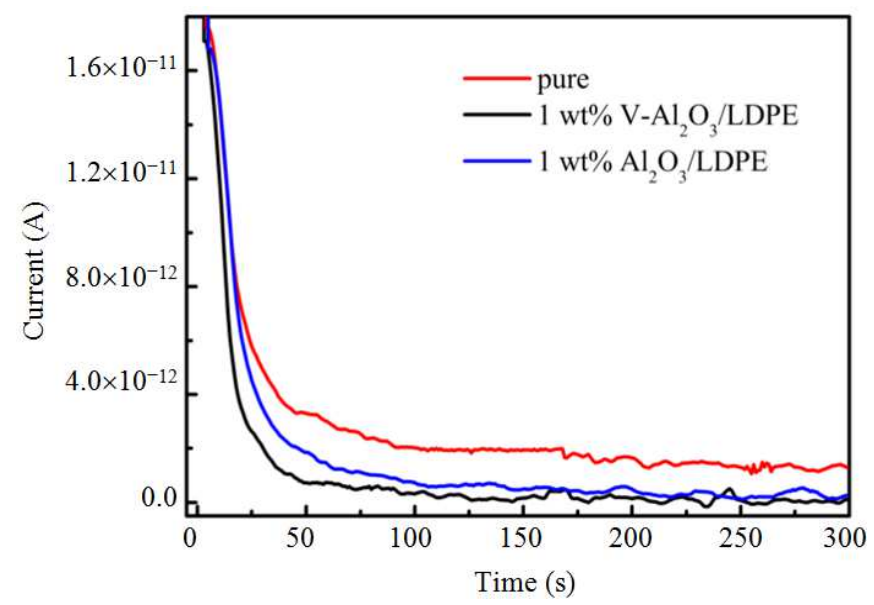

Fig. 2. Polarization currents curves of $\mathrm{Al}_{2} \mathrm{O}_{3} / \mathrm{LDPE}$ and $\mathrm{V}-\mathrm{Al}_{2} \mathrm{O}_{3} / \mathrm{LDPE}$ nanocomposites at the applied of $1 \mathrm{kV}$

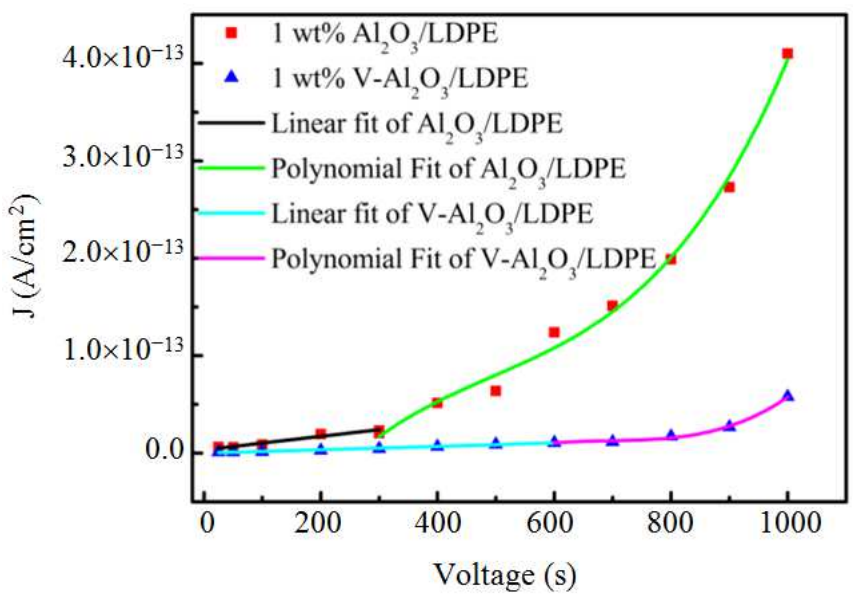

Fig. 3. Current density-voltage $(J-V)$ curves from the equilibrium value of polarization currents at $25-1000 \mathrm{~V}$ of $\mathrm{Al}_{2} \mathrm{O}_{3} / \mathrm{LDPE}$ and $\mathrm{V}$ $\mathrm{Al}_{2} \mathrm{O}_{3} / \mathrm{LDPE}$ nanocomposites

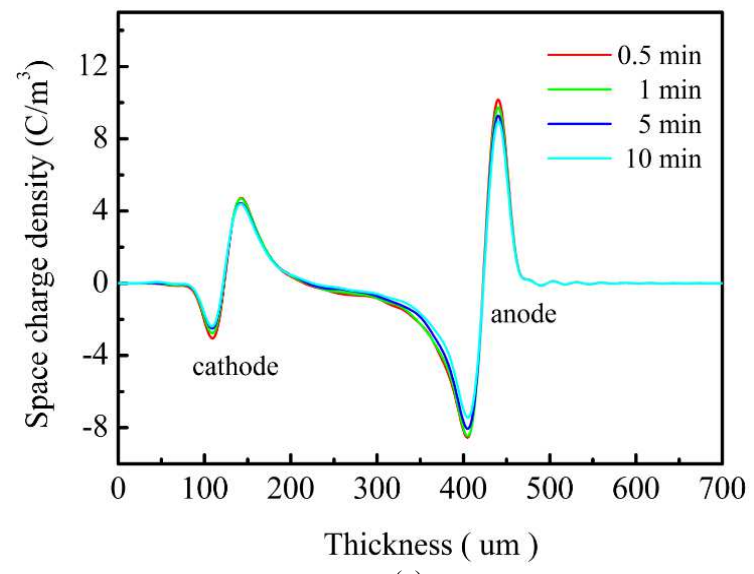

(a)

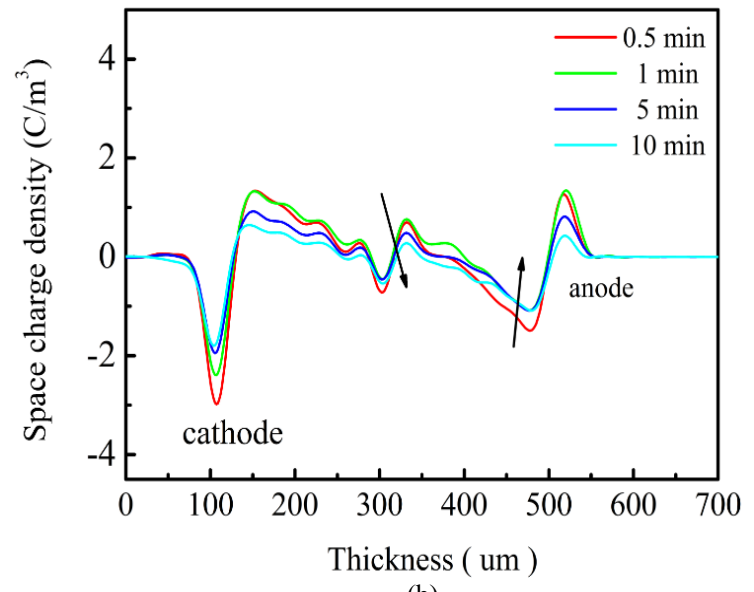

(b) 


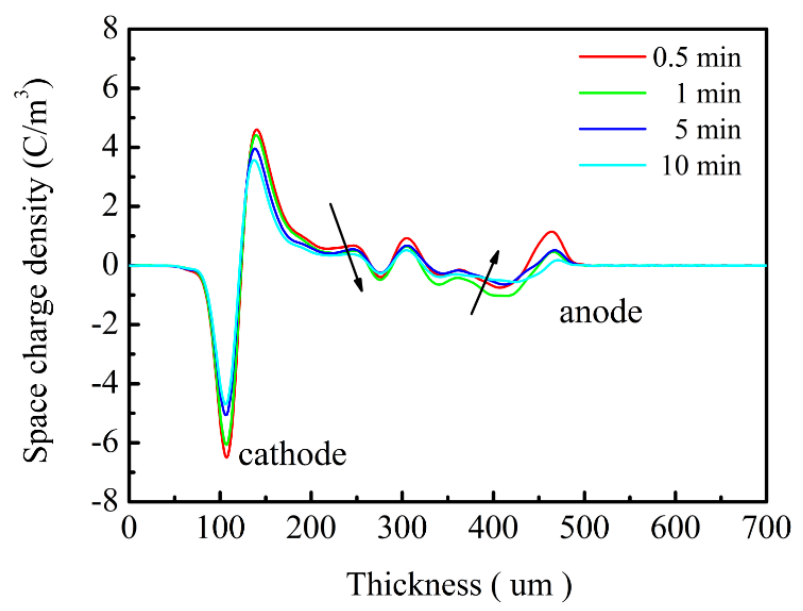

(c)

Fig. 4. Space charge decay after removal of $30 \mathrm{kV}$ stressing in $120 \mathrm{~min}$ on LDPE sample (a) neat $\mathrm{LDPE}$ (b) $\mathrm{Al}_{2} \mathrm{O}_{3} / \mathrm{LDPE}$ nanocomposites (c) $\mathrm{V}-\mathrm{Al}_{2} \mathrm{O}_{3} / \mathrm{LDPE}$ nanocomposites

The space charge decay for both types of LDPE samples are shown in Fig. 4. Both positive and negative charges were introduced into the neat LDPE near the cathode and anode, respectively, was observed in Fig. 4a. Many researchers believe that electrons were injected into the samples from the two electrodes. Fig. $4 \mathrm{~b}$ shows the negative charges in the samples, migrated in the bulk, reducing the height of the positive peak. After $10 \mathrm{~min}$, the negative peak totally disappears at the anode and negative charges are now accumulated in the bulk of samples. The electrons in $\mathrm{Al}_{2} \mathrm{O}_{3} / \mathrm{LDPE}$ composites have a higher mobility than the neat LDPE, they may disappear very quickly. The reason is that the charges move from the anode to the cathode by negative trapped charges. It is likely that a potential energy barrier exists for charges moving from sample to the anode.

As a result, the charges gather near the electrode and some of them get retrapped near the cathode. As can be seen from Fig. 4c, the injected charge in the cathode is fairly smaller than the $\mathrm{Al}_{2} \mathrm{O}_{3} / \mathrm{LDPE}$ composites. It may due to that the silane coupling can enhance the compatibility between LDPE and nano-particles and decrease the defects in the interface.

It makes the nano- $\mathrm{Al}_{2} \mathrm{O}_{3}$ become effective trapping site to fix carriers and decrease the carrier mobility. A charges injected from electrodes generate in the deep trap induced by the nano- $\mathrm{Al}_{2} \mathrm{O}_{3}$ after electric voltage applied. The charges are difficult to move and accumulate near the electrodes to produce an additional electric potential reversed to the applied voltage. It inhibits the dissociation of small molecule and prevents further injection of the charges. Therefore, the space charge inside the sample is reduced.

\section{Conclusion}

In summary, the LDPE nanocomposites filled with the unmodified $\mathrm{Al}_{2} \mathrm{O}_{3}$ and $\mathrm{V}-\mathrm{Al}_{2} \mathrm{O}_{3}$ nanoparticles were prepared by using melt mixing and hot press methods, respectively. The main conclusions are as follows.

Modified nano- $\mathrm{Al}_{2} \mathrm{O}_{3}$ particles show good dispersion in LDPE matrix compared with the unmodified nano$\mathrm{Al}_{2} \mathrm{O}_{3}$ particles.

The addictive nanoparticles bring more deep traps and shallow trap, resulting in the effect of suppressing space charge. The suppressing effect of $\mathrm{V}-\mathrm{Al}_{2} \mathrm{O}_{3} / \mathrm{LDPE}$ nanoparticles is better than that of unmodified one.

The additives of $\mathrm{V}-\mathrm{Al}_{2} \mathrm{O}_{3}$ could decrease the carrier mobility. The $\mathrm{V}-\mathrm{Al}_{2} \mathrm{O}_{3} / \mathrm{LDPE}$ nanocomposites show excellent decay charge effect.

\section{Acknowledgment}

This work was financially supported by NSFC (Grant No. 51207009 and 51377010), the National Basic Research Program of China (973 Program) (Grant No.2014CB239503), Beijing Municipal Science and Technology Commission (Grant No. Z131100005913005), Fundamental Research Funds for the Central Universities (No. FRF-TP-14-016A2) and Visiting Scholarship of State Key Laboratory of Power Transmission Equipment and System Security and New Technology (Chongqing University) (2007DA10512714407).

\section{Author's Contributions}

Si-Jiao Wang participated in all experiments and contributed to the writing of the manuscript. Jun-Wei Zha 
designed the research plan, organized the study, coordinated the data-analysis and contributed to the revising of the manuscript. Yun-Hui $\mathrm{Wu}$ and Hong-Da Yan participated in the experiments. Zhi-Min Dang coordinated the data-analysis and contributed to the revising of the manuscript.

\section{Ethics}

The authors declare no competing financial interest.

\section{References}

Fleming, R.J., A. Ammala, P.S. Casey and S.B. Lang, 2011. Conductivity and space charge in LDPE/BaSrTiO 3 nanocomposites. IEEE Trans. Dielectr. Electr. Insulat., 18: 15-21. DOI: 10.1109/TDEI.2011.5704488

Hosier, I.L., A.S. Vaughan and S.G. Swingler, 2010. An investigation of the potential of ethylene vinyl acetate/polyethylene blends for use in recyclable high voltage cable insulation systems. J. Mater. Sci., 45: 2747-2759. DOI: 10.1007/s10853-010-4262-5

Ju, S., M. Chen, H. Zhang and Z. Zhang, 2014. Dielectric properties of nanosilica/low-density polyethylene composites: The surface chemistry of nanoparticles and deep traps induced by nanoparticles. Express Polymer Lett., 8: 682-691. DOI: 10.3144/expresspolymlett.2014.71

Kim, Y.J., S.T. Ha, G.J. Lee, J.H. Nam and S.H. Nam, 2013. Investigation of space charge distribution of low-density polyethylene/GO-GNF (graphene oxide from graphite Nanofiber) nanocomposite for HVDC application. J. Nanosci. Nanotechnol., 13: 3464-3469. DOI: 10.1166/jnn.2013.7276
Liu, N. and G. Chen, 2013. Changes in charge trapping/detrapping in polymeric materials and its relation with aging. Proceedings of the IEEE Conference on Electrical Insulation and Dielectric Phenomena, Oct. 20-23, IEEE Xplore Press, Shenzhen, pp: 800-803. DOI: 10.1109/CEIDP.2013.6747077

Meunier, M., N. Quirke and A. Aslanides, 2001. Molecular modeling of electron traps in polymer insulators: chemical defects and impurities. J. Chem. Phys., 115: 2876-2881. DOI: 10.1063/1.1385160

Nelson, J.K. and Y. Hu, 2005. Nanocomposite dielectrics-properties and implications. J. Phys. D: Applied Phys., 38: 213-222. DOI: $10.1088 / 0022-3727 / 38 / 2 / 005$

Olthuis, W. and P. Bergveld, 1992. On the charge storage and decay mechanism in silicon dioxide electrets. IEEE Trans. Electr. Insulat., 27: 691-697. DOI: $10.1109 / 14.155784$

Takada, T., Y.J. Hayase and Y. Tanaka, 2008. Space charge trapping in electrical potential well caused by permanent and induced dipoles for LDPE/mgo nanocomposite. IEEE Trans. Dielectr. Electr. Insulat., 15: 152-160. DOI: 10.1109/T-DEI.2008.4446746

Wu, K., Z. Lv, Q.D. Xia, Y. Hong and L.A. Dissado, 2014. Space charge formation and conductivity characteristics of PE and oil impregnated paper under a temperature gradient. Proceedings of International Symposium on Electrical Insulating Materials, Jun. 01-05, IEEE Xplore Press, Japan, pp: 93-96. DOI: 10.1109/ISEIM.2014.6870728 